\title{
¿ES SEGURO EL ABORTO DE CAUSA MÉDICA EN CHILE?
}

En dos editoriales de 2008 y en una de 2009, esta revista ha dado el espacio para analizar el sensible tema del aborto $(1,2,3)$. Esto ha ocurrido por la participación de nuestra Sociedad en un proyecto de carácter mundial de la FIGO que estudia los factores asociados a aborto inseguro e implementar medidas de salud pública para prevenirlo.

La definición de aborto dada por la OMS que tendremos como referencia para el contexto de este artículo es: La interrupción del embarazo antes de la viabilidad fetal con medios adecuados. Esta definición no hace mención si el feto está vivo o muerto. Desde un punto de vista jurídico la consideración de aborto, incluye la muerte fetal como consecuencia de los procedimientos. Estos procedimientos son aceptados en aquellas legislaciones que tienen la despenalización del aborto. No ocurre así cuando el aborto esta penalizado, en la cual los procedimentos de aborto voluntario o la interrupción de la vida embrionaria o fetal están prohibidos y su ejecución constituyen un delito penado por la sociedad, a través de la ley y de los procedimientos del código de Derecho Penal. En casi todos los países del mundo el aborto está despenalizado en ciertas circunstancias, para compatibilizar el principio del respeto a la vida con situaciones extremas que atentan a la salud.

Así se ha definido como aborto de causa médica o por razones de salud a la interrupción del embarazo antes de la viabilidad fetal con medios adecuados, con el objeto de prevenir la muerte de la mujer o de tratar una enfermedad que afecta tanto al feto como a la madre y que hace inviable la vida embrionaria o fetal.

En general esta herramienta se aplica casi universalmente, pues es una indicación gineco-obstétrica que se describe en los textos de medicina de la especialidad. Se le ha denominado incorrectamente como aborto terapéutico, pues conceptualmente, el objetivo no es alcanzar la sanación, sino que prevenir situaciones muy graves en las cuales la no intervención atenta contra la vida de una persona, sin alcanzar el beneficio de la protección de otra vida en proceso de desarrollo, aun incipiente o inicial.

\section{ANÁLISIS DE LA SITUACIÓN EN CHILE DEL ABORTO DE CAUSA MÉDICA}

En Chile hasta 1989, el Código Sanitario en su artículo 119 decía: "Se podrá interrumpir el embarazo por causas de salud de la mujer, para lo cual basta la firma de dos médicos cirujanos". Este procedimiento se aplicaba dos a tres veces por año según los registros de egresos del Servicio Nacional de Salud (4) y por cierto que no se consideraban los procedimientos de rutina que se practican para interrumpir un embarazo ectópico complicado o no complicado, la interrupción de un embarazo molar completo o incompleto o la interrupción de huevo roto con sepsis materna, así como muchas otras serias y graves situaciones y algunas de muy baja frecuencia, que eran objeto de discusiones de indicación médica en los respectivos Servicios de Obstetricia y Ginecología. Estos diagnósticos de egreso quedaban registrados en las respectivas patologías ginecológicas, obstétricas o fetales de acuerdo con la Novena Revisión de la Clasificación Internacional de Enfermedades de OMS (5). Como por ejemplos están: (630) Mola hidatiforme, (631) Otras anormalidades del producto de la concepción, (632) Aborto retenido (633), Embarazo ectópico. El rubro aborto resultante de la aplicación del artículo 119 del código de Derecho Penal se clasificaba en el rubro (635) Aborto inducido legalmente, que era de una frecuencia muy baja como se explicó anteriormente.

La Décima Revisión de 1992 (6), mantiene el rubro (O00-O08) Embarazo que termina en aborto. Pero ya no incluye los términos Aborto legalmente inducido (635) o Aborto ilegalmente inducido (636) y son reemplazados por el rubro Aborto médico (O04).

En septiembre de 1989, la Junta Militar, elimina el artículo 119 por el que dice: "No podrá ejecutarse ninguna acción cuya finalidad sea provocar el aborto". Ley 18.826 que derogó el artículo 119 del 
Código Sanitario.

Esta determinación tan amplia y drástica no consideró la interrupción del embarazo por causas médicas y dejó en una situación de incompatibilidad el sentido común de la medicina con la legislación vigente. La Constitución Chilena en su artículo 19, número 1 dice: La Constitución asegura a todas las personas:

El derecho a la vida y a la integridad física y psíquica de la persona. La ley protege la vida del que está por nacer.

Una de las interpretaciones predominantes que ha tenido el Tribunal Constitucional de Chile, es la extensión del que está por nacer, desde la fecundación del óvulo y que refleja muy bien la interpretación dominante desde que se derogó el artículo 119 ya comentado (7).

Como consecuencia de esta ambigüedad, las interpretaciones del artículo 119, han provocado una confusión en su aplicación. Haciéndola extensiva a las clásicas indicaciones de interrupción del embarazo y consideradas en todos los texto de Medicina y en la Clasificación Internacional de Enfermedades. Se ilustra este punto con lo ocurrido en Chile con la interrupción de un embarazo molar incompleto en el Hospital Salvador, hace algunos años, que alcanzó connotación pública, donde las interpretaciones variaron de lo constitucional hasta lo teológico. O de criterios clínicos de interrupción de un embarazo ectópico tubario, hasta que este no estuviese complicado, con la certeza de la muerte del embrión.

Esta materia cae en los objetivos del proyecto FIGO que da a la oportunidad a los países para revisar las normas relacionadas con el aborto inseguro en su propio contexto. Por cierto que Chile no muestra una mortalidad materna asociada a las complicaciones del aborto clandestino como se ha demostrado en editoriales anteriores. Sabemos que Chile es uno de los pocos países en los cuales se ha demostrado en un estudio cuasi-experimental que la aplicación de la Planificación Familiar basado en los factores de riesgo predictivo, impacta en la disminución de los abortos, sin afectar la natalidad de esas poblaciones (8).

Hay necesidad de analizar en nuestra especialidad las causas de interrupción del embarazo de causa médica. Es indispensable que esta materia no quede sólo a la libre interpretación individual o institucional. Es por ello que los argumentos de las bajas tasas de mortalidad materna y perinatal no justifican revisar el tema médico-legal, son limitados en sí mismo. La calidad y la seriedad del desarrollo de la medicina chilena busca calidad y excelencia. No se puede alcanzar el desarrollo con el silencio de lo que se puede mejorar. Esta es la tarea y el ob- jetivo del Proyecto FIGO. Es una oportunidad que radica sólo en los países. No hay tareas impuestas, ni hipótesis basadas en otras realidades.

Tampoco es oportuno argumentar que la revisión de las leyes en esta materia abre las posibilidades de la discusión de la despenalización del aborto en Chile. Si el argumento es mantener el silencio obligado, frente a situaciones delicadas que afectan a nuestra sociedad, se comenten errores y faltas a la ética por defecto. Debemos enfrentar nuestros problemas y no esconderlos con argumentación pseudocientífica.

Sólo existen cinco países en el mundo en los cuales el aborto es ilegal por cualquier causa y circunstancia: Chile, El Salvador, Guatemala, Malta y Nicaragua. Esto ya nos habla de la excepción.

Una somera revisión de nuestra especialidad muestra que las siguientes situaciones son circunstancias que debemos resolver al amparo de la compatibilidad del ejercicio ético de la medicina y la legislación vigente. Las describo en este editorial para que se discuta y abra el foro de un tema en silencio.

A) Situaciones en los límites de la viabilidad fetal. Desde un punto de vista legal la extracción de un feto vivo inmaduro no es un aborto si el feto, puede ser cuidado en una Unidad de Tratamiento Intensivo, que le ofrecerá mejores condiciones que al interior del útero. Estos casos son muy específicos y se manejan en cualquier servicio de Obstetricia y Ginecología del país y lo que entra en discusión es el momento de la interrupción y la disponibilidad de plaza en una UTI para la atención del recién nacido.

Casos como estos se presentan en:

- Enfermedad metabólica materna gravemente descompensada y sin respuesta al tratamiento, con retardo severo del crecimiento fetal.

- Síndrome hipertensivo del embarazo, severo sin respuesta al tratamiento.

- Insuficiencia renal grave con descompensación materna y fetal.

- Trombocitopenia trombótica materna $(90 \%$ de letalidad materna).

- Monorena trasplantada con rechazo autoinmune del riñón único.

- Herpes gestacional agudo y grave.

- Cáncer cérvico uterino en estadio II o más, para acelerar el tratamiento oncológico específico. El embarazo empeora el pronóstico del cáncer de cuello en la experiencia del Instituto Nacional del Cáncer de Chile (9).

- Otras patologías de muy baja frecuencia.

B) En la no viabilidad fetal ni materna. Hay situaciones en las cuales el embrión es francamente patológico y no tiene ninguna posibilidad de sobrevida. 
En algunos casos, además está en riesgo la vida de la madre y la no intervención significa la pérdida tanto de la madre como del embrión o feto. En general estas situaciones se dan para embarazos por debajo de las 20 a 22 semanas y la mayoría de las patologías ocurren antes de las 10 semanas de embarazo, lo cual no da ninguna alternativa de tiempo para el crecimiento del embrión o del feto y potencial viabilidad extrauterina en una Unidad de Tratamiento Intensivo Perinatal.

Casos como estos son:

- Embarazo ectópico tubario complicado con rotura de la trompa y hemorragia aguda.

- Embarazo ectópico cornual con riesgo de rotura uterina.

- Embarazo ectópico ovárico con inminente riesgo de rotura o ya roto.

- Mola hidatiforme.

- Sepsis materna por rotura del huevo y choque materno.

- Monorena transplantada con rechazo de riñón único.

- Insuficiencia hepática severa y progresiva con ictericia en ascenso.

- Cáncer de ovario avanzado con indicación de tratamiento radiante.

- Insuficiencia renal crónica en descompensación por el embarazo.

- Otras patologías crónicas de muy baja prevalencia.

C) En la no viabilidad fetal por causas genéticas y fallas en el desarrollo embriológico. Son situaciones extremas en las cuales el diagnóstico se hace después de las 16 a 20 semanas y el feto, aunque continúe su desarrollo, no tiene ninguna alternativa de sobrevivencia al poco tiempo de nacer. La mujer debe ser informada de la situación tanto por razones legales como éticas.

Casos como estos son:

- Anencefalia.

- Encefalocele.

- Monstruosidades: cíclopes y monstruosidades dobles.

- Agenesia del cuerpo calloso.

- Agenesia del cerebelo.

- Gemelos acárdicos.

La ley actualmente vigente no se aplica, pues muchas de las indicaciones de interrupción del embarazo de causa médica, se practican en forma rutinaria, tanto en el sector público como privado, más aun en las situaciones de emergencia donde se pone en riesgo la vida de la madre y donde el embrión o feto no tiene ninguna posibilidad de sobrevivencia.

Hoy la medicina en Chile, ya no discute el tema si se debe optar por la vida de la madre o la del feto.
Cuando el caso es de discusión netamente médica, y el feto tiene 25 semanas o más, se tiene la alternativa de interrumpir el embarazo con el apoyo y los cuidados de una Unidad de Tratamiento Intensivo Perinatal.

Cuando el embrión o feto no es viable y el caso clínico indica que la No interrupción significa una muerte de ambos, pues el embrión o feto no tiene alternativas de esperar viabilidad para ser tratado en una UTI neonatal, la decisión en la mayoría de los casos es la interrupción, dado que la ley es inoperante para proteger a la Sociedad. Pero es el profesional el que asume la responsabilidad. Tampoco es un adecuado argumento para no analizar esta situación, el que no existan casos de demandas a colegas en algunas de estas circunstancias. Esto es un argumento que se revierte con la primera demanda que ocurra, si es que ya no ha ocurrido.

Profesor Dr. Ramiro Molina Cartes. Miembro del Comité de la SOCHOG en el Estudio FIGO.

Facultad de Medicina de la Universidad de Chile. Presidente de la FIGIJ.

\section{REFERENCIAS}

1. Faúndes A. La Iniciativa de FIGO para la prevención del aborto inseguro. Rev Chil Obstet Ginecol 2008;73(4):221-2.

2. Donoso E. ¿Unsafe abortion en Chile? Rev Chil Obstet Ginecol 2008;73(6):359-61.

3. Castro R. Iniciativa FIGO de Prevención del Aborto Inseguro: Visión desde el Ministerio de Salud. Rev Chil Obstet Ginecol 2009;74(2):73-6.

4. Molina R. El aborto en Chile. En: Molina R, Orellana M, López J, Muñoz H, Orlandi E, Alarcón J. Elementos de Salud Materna y Perinatal. Colección temas básicos de pediatría. Editor: Meneghello J. Editorial Andrés Bello, 1981.

5. WHO, International Classification of Diseases Ninth Revision, Geneve, 1975.

6. WHO Décima Clasificación Internacional de Enfermedades, Ginebra,1992. Hallado en: http://www.iqb. es/patologia/toc01.htm

7. Requerimiento de inconstitucionalidad deducido en contra de algunas disposiciones de las "Normas Nacionales sobre Regulación de la Fertilidad", aprobadas por el Decreto Supremo № 48, de 2007, del Ministerio de Salud.18/04/2008. Hallado en: http://www.tribunalconstitucional.cl/index.php/sentencias/busca_basico

8. Molina R, Pereda C, Cumsille F, Martinez Oliva L, Miranda $\mathrm{E}$, Molina T. Prevention of Pregnancy in HighRisk Women: Community Intervention in Chile. In: Abortion in the Developing World. Mundigo A, Indriso C. (eds). Editorial WHO. Vistaar Publication. New York, 1999.

9. Castro P, Yazigi, R, Prado S, Garrido J, González M. Cáncer cérvicouterino y embarazo: experiencia del Instituto Nacional del Cáncer. Rev Chil Obstet Ginecol 2004; 69(4):274-8. 